\title{
FEEDBACK AND FEED-FORWARD FOR PROMOTING PROBLEM-BASED LEARNING IN ONLINE LEARNING ENVIRONMENTS
}

\author{
${ }^{1}$ Ashley Webb \& ${ }^{2}$ Mahnaz Moallem \\ ${ }^{1}$ Innovative Research \& Training (iRT), USA \\ ${ }^{2}$ Watson College of Education \\ University of North Carolina Wilmington, USA \\ ${ }^{2}$ Corresponding author: moallemm@uncw.edu
}

\begin{abstract}
Purpose - The study aimed to (1) review the literature to construct conceptual models that could guide instructional designers in developing problem/project-based learning environments while applying effective feedback strategies, (2) use the models to design, develop, and implement an online graduate course, and (3) assess the efficiency of the models.
\end{abstract}

Method - Quantitative and qualitative data were gathered during the implementation of an online graduate-level course that was designed and developed using the two proposed conceptual models. Eleven students were enrolled in the course. Multiple sources of data and analytical strategies were used to collect, analyze, and interpret the data.

Findings - The results show that the characteristics and strategies suggested in the proposed models supported student achievement in course projects and activities. The timely and frequent feedback allowed students to make necessary changes to their final project parts and improve performance. The motivating, informative/ specific feedback and feed-forward goals appeared to provide a reference for areas of student improvement. A balance of the three types of feedback, along with metacognitive questioning, supported student improvement. Because the frequency of feedback was dependent upon student request, those who needed more frequent 
feedback during the acquisition of learning benefited from that, but those who did not need it received the moderate amount necessary to be successful.

Significance - The study brings to light the importance of three types of formative feedback in problem or project-based learning. It offers two conceptual frameworks for instructional designers and curriculum developers. The models could be used to provide all forms of feedback including feed up, feedback and feed-forward to support student success in PBL learning environments.

Keyword: Problem-based learning, Project-based learning, feedback and feed-forward, online learning.

\section{INTRODUCTION}

Problem-based learning (PBL) was first developed in 1960 in medical education with the aim of situating learning in a meaningful task, such as case-based instruction and project-based learning (HmeloSilver, 2004). As a student-centred learning environment, PBL was developed to bridge the gap between what is learned in school and its relevance for future professional practice (Wijnia, 2014). PBL starts with authentic, real-world problems or situations rather than the exposition of knowledge. Problems are used as tools to achieve the required knowledge and the problem solving skills necessary to eventually solve the problems (Barrows, 1996). Under the guidance of a facilitator, small groups of students work together to analyze the problems, formulate learning issues for further self-study, and then collaborate as a group to solve the problem.

Project-based learning (PrBL) has often been viewed as synonymous with PBL. While there are some historical differences between the two approaches (Ertmer \& Simons, 2006), scholars argue that problem-based learning is a type of project-based learning (Larmer, 2014). A comparison of problem-based and project-based learning suggests that the essential components of project-based learning align with the following five PBL criteria: 1) it is a student-centred approach, 2) it starts with authentic and real world problems or tasks, 3) it requires collaboration and group work, 4) it has a 
multidisciplinary orientation, and 5) it is guided by facilitators or tutors. The major differences between PrBL and PBL include: 1) project tasks are closer to professional reality, thus take a longer period of time to solve, 2) project tasks result in concrete products, 3 ) embedded in the large problems or projects are smaller problems to be solved, and 4) projects are more directed to the application of knowledge rather than acquisition of knowledge (Perrenet, Bouhuijs $\&$ Smits, 2000).

Both PBL and PrBL approaches promise to support the transfer of knowledge and skills from the classroom to the workplace. PBL and PrBL (Barrows, 1996; Marx, Blumenfeld, Krajcik, \& Soloway, 1997) focus on providing carefully selected or designed problems or challenges that require learners to apply domain-specific and domain-general knowledge, self-directed learning strategies and team participation skills. Whether solving a complex problem or using the design process to develop a new product while resolving arising issues, learners apply their cognitive skills to an increasingly varied set of real-world contexts and settings (van Merriënboer, Clark, de Croock, 2002). This would assist them in transferring their knowledge, skills and attitudes from the school setting to real world contexts (Clark, Kirschner \& Sweller, 2012; Sweller, Kirschner \& Clark, 2007). Recently, both approaches have become progressively more popular in higher education settings. In this article, we use PrBL as an overall curriculum focus and PBL as an embedded problem solving approach to achieve the goals of the final project or task.

\section{The Problem}

Despite the many appealing characteristics of PBL and PrBL, there are ongoing disputes about the degree to which students should be supported or guided with adequate feedback during the problem solving or product development process. On the one hand, research shows that both of these approaches are most effective when appropriate learning goals are defined; formative, continuous and effective feedback are provided; and multiple opportunities for selfassessment, peer-assessment and reflection are offered. Evidence further suggests that without explicit instructional guidance and feedback capable of enhancing the learning process (Nicol \& MacFarlane-Dick, 2004), it is likely that the underlying concepts 
and skills that students are required to learn will not be achieved. On the other hand, instructional support and formative feedback that can generate beneficial information for students could take many forms, and are still not well-articulated, particularly in web-based learning environments. A review of the literature shows that the effectiveness of feedback is reliant on several factors such as models of feedback, modes of feedback, forms of feedback, the timing of the feedback, and the ability and skills to give and receive effective feedback. However, how feedback should be implemented in PBL learning environments needs further exploration and articulation.

The main purposes of this study were to (1) use the literature to build conceptual models that could guide instructional designers to integrate effective feedback and feed-forward in the design and development of an online graduate-level course utilizing problem/ project based learning; and (2) to assess the utility and impact of the models on student learning and satisfaction.

\section{LITERATURE REVIEW}

An extensive review of the literature was conducted, and the results were synthesized to develop two conceptual models for the above purpose. The following sections summarize the areas of review.

\section{Feedback}

Feedback is an essential component of learning and understanding which is commonly thought of as the information given to students about the quality of performance (Cohen, 1985; Sadler, 1989). It often fulfills both summative and formative purposes and is delivered both through written text and verbal commentary (Price, 1997). The difference between summative and formative feedback is in their purpose and effect (Sadler, 1989). The purpose of summative feedback is to provide information on how well a student has achieved particular major learning targets (Nitko, 2004). These learning targets are typically those that are to be mastered at the end of a unit of instruction and can only inform for subsequent learning. Summative feedback generally includes a grade or mark as well as comments that provide insights on why the particular 
mark is given. The primary purpose of formative feedback, on the other hand, is to allow the student to look at their current pieces of work, make adjustments to that work, and to carry those strategies to future work. Formative feedback is continuous and involves gathering information about students' progress throughout a unit of instruction (Nitko, 2004) with the intention of improving learning (Sadler, 1998). To be effective, formative feedback should provide information about the gap between actual performance and some established standard of performance (Johnson \& Johnson, 1993).

\section{Formative Feedback, Feed-up and Feed-forward}

Formative feedback can signal a gap between a current level of performance and some desired level of performance or goal. Resolving this gap can motivate higher levels of effort (Song \& Keller, 2001). That is, formative feedback can reduce uncertainty about how well (or poorly) the student is performing a task (Ashford, 1986; Ashford, Blatt, \& VandeWalle, 2003). According to Sadler (2010), "if feedback is to have a reasonable prospect of achieving its formative purpose, it has to be both specific (referring, as it necessarily does, to the work just appraised) and general (identifying a broader principle that could be applied to later works)" (p. 3).

Feed-forward provides guidance before students attempt their assessment task (Hendry, White \& Herbert, 2016). By definition feed-forward is timely and future-oriented in relation to the upcoming task. It includes giving students 'tips' or guidance about what not to do based on previous performance and involving students in judging the quality of their work (Hattie \& Timperley, 2007; Nicol \& Macfarlane-Dick, 2006).

Hattie and Timperley (2007) argue that feedback and feed-forward strategies can be first applied by answering the following three questions to offer a feed-up.

1. Where am I going? What are the goals and how can I attain them?

2. How am I doing? Am I meeting the said goals and how is my current performance? and

3. Where to next? What can I do to prepare or better understand for future tasks? 
These three questions assure that the feedback helps explain what quality performance is (feed-up), provides opportunities to close the gap between current and desired performance (feedback), and helps the student see the next steps in learning and how to undertake them (feed-forward) (Hattie \& Timperley, 2007; Nicol \& MacfarlaneDick, 2006). This strategy for developing comprehensive feedback, however, may not be enough to close the gap. Students must be able to act upon this feedback to make changes to their own work. Problems may arise if students have difficulty understanding the comments or knowing how to act upon the suggestions (Carless, Salter, Yang, \& Lam 2011). Feedback then cannot be only about telling and dispensing information to the learner (Sadler, 2013). For feedback and feed-forward to be successful, a set of characteristics must be present in order to close the gap between the learners current and desired performance.

Feedback, feed-up and feed-forward can be provided in various forms (written, oral, dialogical), offered immediately/delayed, frequently or in a timely manner, serve different functions (directive, facilitative, specificity) and come from a variety of sources (instructor's one-onone interaction, instructor's small group interaction, peers and self). See Appendix A for the synthesis of the literature in each of these areas.

\section{Problem-Based and Project-Based Learning}

Both PBL and PrBL involve a general process and a set of characteristics that ensure the learning experience provided to the learner is student-centred (Barrows, 1996) and that learners are engaged in authentic problems that will encourage learning, metacognition, and self-regulation (Torp \& Sage, 2002). Table 1 summarizes the characteristics and the process of implementing PBL or PrBL.

\section{The Instructor's Role in PBL}

The facilitator's/instructor's role in PBL is critical to successful implementation and requires careful facilitation of the learning rather than just delivering the content (Savery, 2009). This facilitative role requires instructors to develop learning goals with the students 
(Markham, Larmer \& Ravitz, 2003), monitor the learning process to ensure that no phase of the learning process is being overlooked, and encourage the students' active participation (Barrows, 1988). The instructor/facilitator must constantly probe the students with questions to challenge their understanding of the problem and guide them to the deeper levels of understanding (Savery \& Duffy, 1995; Barrows, 1988). Another significant role for instructors is to provide frequent milestones for students to measure success and afford opportunities for formative assessments and feedback throughout the learning experience to monitor progress (Markham, Larmer, \& Ravitz, 2003; Barrows, 1988). Barrows (1988) suggests that "focused metacognitive questions" (p. 10) can be used to probe the students in the areas where they may be having difficulty, therefore increasing the students' ability to notice these inadequacies in future learning. Finally, the instructor must continuously provide opportunities for students to discuss, reflect and evaluate their learning (Markham, Larmer \& Ravitz, 2003).

Table 1

Characteristics and process of implementing PBL or PrBL

\begin{tabular}{lc}
\hline Characteristics & Process of Implementation \\
\hline - Problems/Tasks must be & $\bullet$ The students define the problem/ \\
authentic, open-ended, aligned & task, and a clear set of learning \\
with curriculum standards, & goals is developed. \\
and must integrate multiple &
\end{tabular}
disciplines.

- The problem should engage

- Students become actively students in a comfortable cognitive conflict or dissonance as well and should utilize vital workplace skills and enhance student self-regulatory skills.

- The instructor facilitates, coaches, and or supports the development of the students' metacognitive processes to develop the "problem-solver." engaged with the problem as stakeholders and generate possible ideas and solutions using present levels of knowledge.

- Students must conduct research or inquiry to fill in the gaps and acquire the knowledge and skills necessary to solve the problem. 


\begin{tabular}{|c|c|}
\hline Characteristics & Process of Implementation \\
\hline $\begin{array}{l}\text { Requires the application of both } \\
\text { domain-specific and domain } \\
\text { general knowledge to solve or } \\
\text { develop the product. }\end{array}$ & $\begin{array}{l}\text { - Students continue to generate } \\
\text { an exhaustive list of solutions } \\
\text { and choose the best based on } \\
\text { close analysis of data collected } \\
\text { during research and inquiry. The } \\
\text { solution can be presented as a } \\
\text { product, performance, or event. }\end{array}$ \\
\hline $\begin{array}{l}\text { Opportunities for collaborative } \\
\text { learning environments should be } \\
\text { provided. }\end{array}$ & $\begin{array}{l}\text { - Authentic assessments are } \\
\text { used throughout the learning } \\
\text { process allowing students to } \\
\text { demonstrate their learning. }\end{array}$ \\
\hline $\begin{array}{l}\text { Promotes } 21^{\text {st }} \text { Century learning } \\
\text { skills such as communication, } \\
\text { collaboration, creativity, and } \\
\text { critical thinking. }\end{array}$ & $\begin{array}{l}\text { Frequent debriefing activities } \\
\text { (group meetings, journaling, } \\
\text { etc.) take place to ensure } \\
\text { reflection is occurring and key } \\
\text { concepts are being learned. } \\
\text { (Barrows, 1988; Barrows, 1996; } \\
\text { Larmer \& Mergendoller, 2013; } \\
\text { Savery, 2009; Savery \& Duffy, } \\
\text { 1995; Torp \& Sage, 2002). }\end{array}$ \\
\hline
\end{tabular}

\section{PrBL or PBL in Online Environments}

Online learning, also known as web-based instruction, occurs when instructional design strategies utilize the World Wide Web as a resource to integrate a variety of information and for collaboration and communication of ideas (Relan \& Gillani, 1997). Distance education is often an added component to online learning and involves instruction that takes place when the learning group is separated by space and or time and where telecommunication systems are used to connect the learners, resources and instructors (Simonson, Smaldino, Albright, \& Zvacek, 2015). Because PBL/ PrBL requires frequent collaboration, communication and various forms of information and resources, it is essential that the virtual learning environment provides a set of learning and teaching tools to support this. These tools should enhance the students' learning experience rather than hinder it, and can include synchronous and asynchronous methods such as email, webcasts, discussion boards, learning management systems and teleconferencing (Savin-Baden \& Wilkie, 2006). 
There are often challenges to creating effective PBL instruction in an online environment. First, for instructors, it can be difficult to manage the resources and information necessary while also engaging students in a collaborative online process (Savin-Baden \& Wilkie, 2006). The separation of the instructor, peers, and the student can also make collaboration over an authentic problem difficult. Space and time limit the amount of interactions and the ability to meet as groups to effectively plan and manage group activities. A student's motivation and responsibility for his/her own learning also presents a problem. Learners often already feel that a large amount of autonomy is necessary in PBL as well as in an online environment. When combined, students can feel overwhelmed and experience loss of control (Savin-Badin \& Wilkie, 2006; Simonson, Albright \& Zvacek, 2015).

\section{Feedback in PBL/PrBL: Design Models}

Analysis and synthesis of the literature provided the basis for constructing two conceptual models to guide instructional designers in integrating effective feedback, feed-up, and feed-forward in the design and development of an online graduate level course utilizing problem/project based learning. The proposed models presented in Figure 1 and Figure 2 originate from principles and ideas reviewed in the literature, but each focuses on different processes in designing instruction for PBL/PrBL. Figure 1 depicts a model that an instructional designer can use to shape a course to meet the needs of supportive feedback in PBL/PrBL environments by ensuring that all of the necessary characteristics of feedback are present. Figure 2 provides a model that shows the process used to implement a feedup, feedback and feed-forward loop to ensure continuous learning and performance improvement in a PBL environment.

The model in Figure 1 uses the principles of PBL/PrBL to develop a set of characteristics for feedback necessary to support achievement and ongoing learning in PBL. The implementation of these characteristics is further clarified with suggestions on how designers can apply them. 


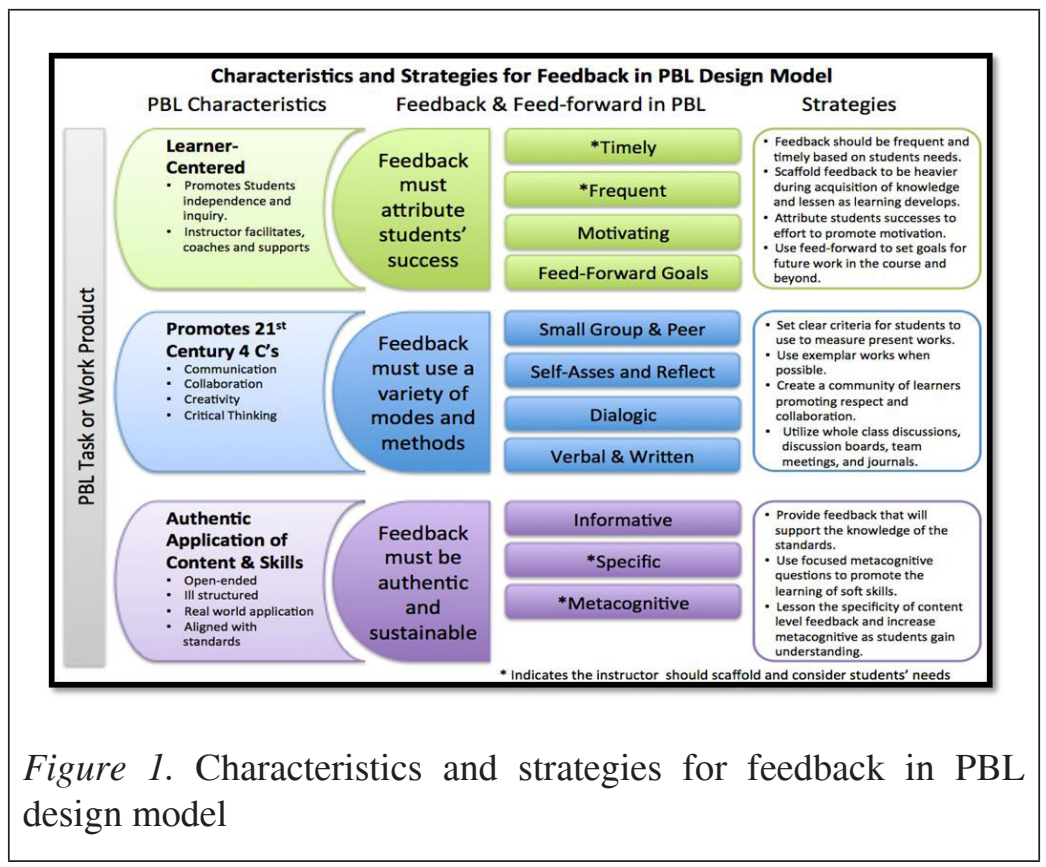

Figure 2 depicts a model of the feedback loop that can be used to foster student learning in a PBL environment. This loop employs the concepts of feed-up, feedback and feed-forward to provide ongoing support, facilitation and coaching by the instructor, peers, and learners themselves. Feed up in this model is defined as the information established about the attainment of the learning goals. This involves providing clear success criteria and setting goals for ongoing learning within the course or PBL/PrBL process. It must be noted that the success criteria and goal setting do not have to be provided by the instructor and that collaborative student development of these items is encouraged in PBL. Feedback is defined as the information provided about performance in relation to the criteria or goals. This written or verbal feedback can be done by the instructor or coach, but can also involve peer, small group, and self-assessment feedback strategies. Feed-forward is defined as information given to learners that leads to future goal attainment. Although not required, feed-forward strategies can best be employed when engaging in dialogue between an instructor and the learner. This allows the learner to help build these learning goals with the instructor, ask clarifying questions, and discuss how they will apply them to future works. Through this dialogue and the setting of goals for future 
learning, students will develop and improve on metacognitive skills such as planning, evaluating, and making adjustments. It is important to note that this feedback loop is continuous throughout the PBL process and does not start or end at any clear point.

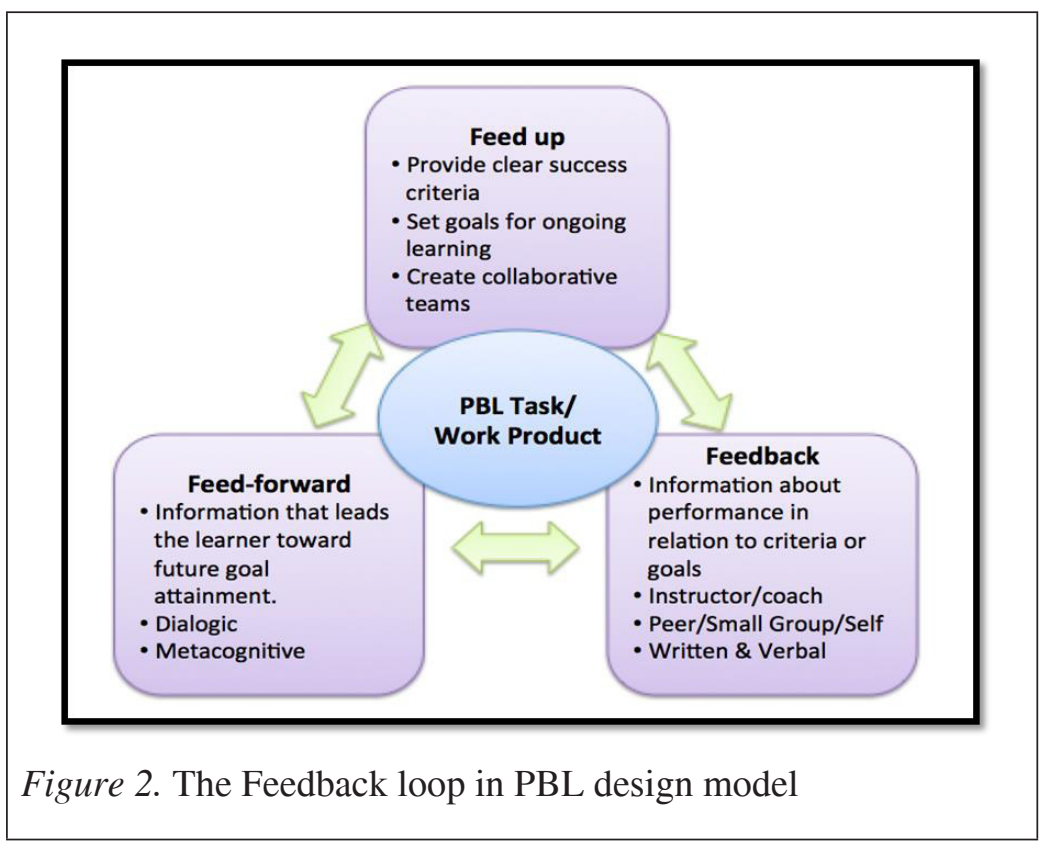

\section{Applying the Proposed Models to an Online Graduate Course}

\section{Course Description}

An online graduate-level course was selected to test the application of the proposed models. The course is entitled "Organization and Management of Instructional Technology" and is designed using the PBL model as its framework. It is an elective course offered to students in an instructional technology graduate programme. Participants enrolled in this course are primarily graduate students seeking a master's degree or a certificate in instructional technology, particularly those who have chosen public and private education as their programme track. The course closely examines the planning and management of a technology change in public or private schools as well as other organizations. Applying the PBL approach, students are engaged in a series of authentic problem-solving tasks and collaborative team activities that lead up to a culminating project. 
The culminating project is divided into three main sections that are due at various points throughout the semester and requires students to build on previous sections to form the final culminating product.

The course is delivered using Blackboard learning management system (LMS) along with WebEx synchronous learning tools to provide both synchronous and asynchronous learning opportunities to students at a distance as well as in a face-to-face classroom. WebEx allows classes to hold a whole group discussion as well as breakout rooms for team meeting areas. A total of 11 students were enrolled in the course during the implementation of this study. The designer of the course was also the instructor for the course delivery.

\section{Course Design Features}

As previously mentioned, this course was designed using the PBL instructional design method to allow learners to apply skills and knowledge to the practical application of an actual technology change project. To support the PBL process, specific characteristics and strategies for feedback were also implemented throughout the course as conceptualized in the Figure 1 model. These included strategies that provided evidence of applying learner-centred approach, promoting opportunities for critical thinking skills, and providing authentic application of content and skills (see Table 2).

Table 2

Application of the Feedback Model in a Graduate Level Online PBL Course

\begin{tabular}{|c|c|c|}
\hline $\begin{array}{l}\text { PBL } \\
\text { Characteristic }\end{array}$ & $\begin{array}{l}\text { Feedback } \\
\text { Characteristic }\end{array}$ & $\begin{array}{l}\text { Strategies Applied in Online } \\
\text { Graduate Course }\end{array}$ \\
\hline \multirow[t]{2}{*}{$\begin{array}{l}\text { Learner Centred } \\
\text { Feedback } \\
\text { must attribute } \\
\text { students' success } \\
\text { and promote } \\
\text { independence. }\end{array}$} & Timely & $\begin{array}{l}\text { - Larger project is broken down into } \\
\text { smaller parts and learning modules with } \\
\text { complimentary activities. } \\
\text { - Feedback is given before another } \\
\text { activity begins. }\end{array}$ \\
\hline & Frequent & $\begin{array}{l}\text { - Weekly feedback is provided } \\
\text { throughout the course that builds on } \\
\text { each other for the final product. }\end{array}$ \\
\hline
\end{tabular}

(continued) 


\begin{tabular}{llc}
\hline PBL & $\begin{array}{l}\text { Feedback } \\
\text { Characteristic }\end{array}$ & $\begin{array}{l}\text { Strategies Applied in Online } \\
\text { Graduate Course }\end{array}$ \\
\hline & Motivating & • Attribute students' success to effort. \\
& "I think your model is appropriate \\
because..." \\
" "You did a good job of explaining \\
how you will..."
\end{tabular}

Feed-Forward Goals

\section{Promotes $21^{\text {st }}$ Century Skills \\ Feedback must use a variety of modes and methods.}

\section{Small Group and Peer}

Self-Assess and Reflect
Verbal and Written
- Offer information about strategies or processes to improve on future tasks or set goals.

○ “. . . you need to make sure you are putting emphasis on the outcome and not so much the process"

- "[t]hink about it and make sure you improve your argument when writing [the] final tech plan."

- Dialogue in which peers are encouraged to openly make suggestions about other teams' work.

- Discussion board posts in Black Board LMS where students can provide peer feedback.

- Students use success criteria provided to measure how they feel they performed on a given task.

- Reflection and self-assessment is encouraged but not assigned.

- Reflective dialogue at the beginning of each synchronous class reported by each team to the whole group.

- Verbal feedback is given weekly via whole group discussion and one or more times during team meetings.

- Written feedback is provided for all three project submissions and many practice activities.

Dialogic - Discussions during synchronous classes among peers and the instructor on how the projects were progressing, areas for improvements, and successes. 


\begin{tabular}{llc}
\hline PBL & Feedback \\
Characteristic & Characteristic & $\begin{array}{l}\text { Strategies Applied in Online } \\
\text { Graduate Course }\end{array}$ \\
\hline Authentic & $\begin{array}{l}\text { Informative } \\
\text { apd Specific }\end{array}$ & $\begin{array}{c}\text { Feedback is given which supports the } \\
\text { learning of content. }\end{array}$ \\
Content \& Skills & $\circ$ "You explain your change model, \\
but do not explain how you would \\
use the model to assist you in \\
planning and implementing the \\
change." \\
" "You might need to think about the \\
sequence of your training, and the \\
staff might need a more hands on \\
approach."
\end{tabular}

Metacognitive - Feedback is given in the form of questions which guides the learner to elaborate or clarify ideas.

○ "What should you expect after one year?"

○ "What is the outcome goal you are trying to achieve?"

\section{The Impact of the Feedback Models on Student Performance and Satisfaction}

\section{Research Questions}

The purpose of this study was to use the literature to build a conceptual model to integrate effective feedback, feed-up and feedforward in the design, development and implementation of online courses, and then test the model in an online graduate level course utilizing PBL. The latter part of the study was specifically focused on the following questions:

1. How was the course addressing feedback, feed-up, and feedforward characteristics and strategies to support PBL?

2. How were students utilizing feedback opportunities?

3. What were students' perceptions about the feedback and feedforward provided in the course?

4. How did feedback and feed-forward strategies influence student performance and satisfaction? 


\section{Participants}

The results presented in this study are based on both quantitative and qualitative analysis of data gathered from 11 graduate level students (10 females and 1 male) enrolled in one semester of a webbased course. The majority of the students worked full time during the day and were part-time graduate students with job experience in education, business, journalism, marketing, programming, and health care. The students' age ranged from 29 to 50, with $62 \%$ with a college degree and $37 \%$ with a post-college degree. For the course, students worked in teams of two with the exception of one student working on the project alone. There were six teams in total for this course.

\section{Data Collection Methods}

Data was collected using a variety of methods over the course of the semester. See Table 3 for the data-gathering strategies.

Table 3

Summary of Data Collection Methods

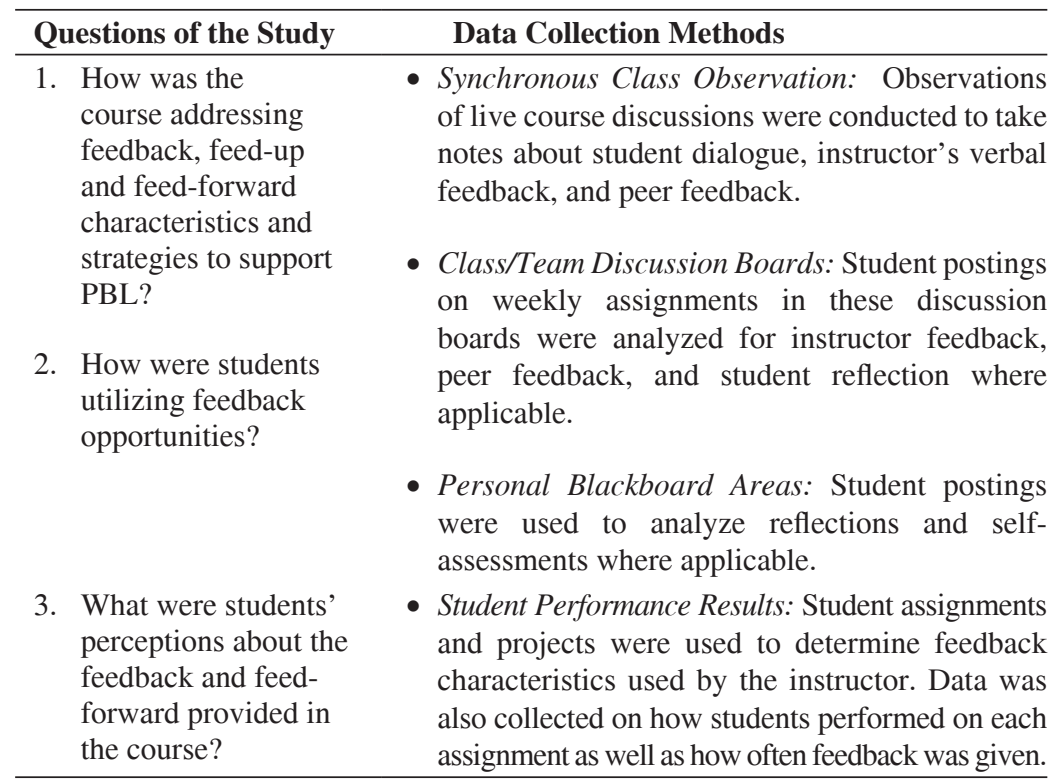

(continued) 


\begin{tabular}{|c|c|}
\hline Questions of the Study & Data Collection Methods \\
\hline $\begin{array}{l}\text { 4. How did feedback } \\
\text { and feed-forward } \\
\text { strategies influence } \\
\text { student performance } \\
\text { and satisfaction? }\end{array}$ & $\begin{array}{l}\text { - Student Survey: An online survey was given to } \\
\text { students near the end of the semester. This survey } \\
\text { included questions about student demographics, } \\
\text { the perception of the feedback provided in the } \\
\text { course, and the overall satisfaction with the } \\
\text { feedback used. Satisfaction was rated on a } \\
\text { 5-point scale as follows: 0=N/A, 1=Strongly } \\
\text { Disagree, 2=Disagree, 3=Neutral, 4=Agree, } \\
\text { 5=Strongly Agree }\end{array}$ \\
\hline
\end{tabular}

Qualitative data was gathered using notes from synchronous class observations, entries from class and team discussion boards, instructor feedback on assignments, and open ended survey questions. This data was examined for student/instructor dialogic feedback, and instructor's verbal and written feedback. During the live synchronous class observations, notes were taken on what the students and instructor said during instances of feedback. If the notes were not clear enough to get the direct quotes due to speed of conversation, course recordings were used to clarify.

\section{Analysis}

Quantitative data was analyzed using SPSS software application. Qualitative data was coded using the following rubric (see Appendix B for examples).

- Motivating: If the comment attributed the students' success to effort.

- $\quad$ Feed-Forward: If the comment offered information about strategies or processes to improve on future tasks or set goals

- Informative/Specific: If the feedback directly supported the learning of the content

- $\quad$ Metacognitive: If the feedback was given in the form of a question to guide the learner to elaborate or clarify.

Using the above list of feedback characteristics, each of the feedback comments (phrases; sentences) made by the instructor was read and coded. The comments were analyzed for their characteristics, and each segment of the comment was assigned to the appropriate category. Once complete, a comparison was made between the total number of feedback comments and the total number of comments 
in each category to calculate a percentage. It should be noted that the percentages were only based on the information gathered during small class segments over the semester, totaling roughly 30 minutes. Long feedback segments of dialogue with multiple statements were counted as one feedback comment unless the feedback shifted from one characteristic to another. For example, if the instructor spoke for three minutes, giving informative/specific feedback to clarify a point, and then ended with a metacognitive question, these counted as two comments (one for each category).

The same method was used to code the class team and discussion boards, the instructor feedback on assignments (see Appendix B for examples), and the open-ended survey questions. Comments were read, analyzed, and categorized based on feedback characteristics. The totals were counted. The data was coded by one of the researchers. The two researchers then met, reviewed portions of the coding for data sources and if there was disagreement, discussed the coded segments of the data and coded them again.

\section{Findings}

\section{How was the course addressing feedback, feed-up and feed-} forward characteristics and strategies to support PBL? Tables 4 and 5 show the frequency and/or method with which various feedback (also see Figure 1) were addressed throughout the semester of the graduate level online PBL course. Table 4 summarizes the characteristics of feedback present when written forms are used. To gather this data, the researchers looked at the written feedback on all papers submitted (both final and draft forms) to determine the timing and frequency of motivating, feed-forward, informative or specific, and metacognitive feedback. The results show that feedback was timely, with all reviews being delivered to students within 10 days or less of project or draft submission. Feedback frequency was dependent upon student request (discussed further in the next section), but at least two extensive forms of written feedback were given to students up to the point of data collection. As shown in Table 4, the majority of the written feedback for this course was informative/specific or motivating. Feed-forward and metacognitive feedback was given less often, although not by a 
large percentage. It is also evident that feed-forward comments occurred more frequently during the review of student drafts rather than on final projects. This is probably because drafts are used to improve the performance of a final product, and feed-forward goals are effective at achieving this goal.

Table 4

Written Feedback Characteristics in the Course (see examples in Appendix B)

\begin{tabular}{lll}
\hline & & \multicolumn{1}{c}{ Occurrence } \\
\hline Timely & - & $\begin{array}{l}\text { Project draft feedback given within 0-7 days of stu- } \\
\text { dent request. }\end{array}$ \\
& - & Final project feedback received within 10 days of \\
student submission.
\end{tabular}

Table 5 shows the characteristics of feedback applied during verbal or dialogic portions of the course. To gather this data, observations were conducted during dialogic feedback portions of the whole group live asynchronous classes. These small segments of various classes totaled approximately 30 minutes. According to the data in Table 5, the instructor utilized metacognitive questioning and informative/ specific feedback to students most often during verbal feedback dialogue. It is possible that the frequent use of these methods was because conversation lends itself to metacognitive questioning as well as clarification of information that is not understood. Feed- 
forward goals and motivating comments occurred less often, but were a small part of the dialogic conversation.

\section{Table 5}

\section{Verbal/Dialogic Feedback Characteristics in the Course}

\section{Occurrence}

\begin{tabular}{lll}
\hline Timely & $\bullet$ & $\begin{array}{l}\text { Weekly dialogic feedback through class discussions } \\
\text { immediately following class assignments and project } \\
\end{array}$ \\
& work. \\
Frequent & $\begin{array}{l}\text { Weekly dialogic feedback given through class } \\
\text { discussions. }\end{array}$ \\
Motivating & $\bullet$ & $14 \%$ of comments were motivating. \\
Feed-Forward Goals & $\bullet$ & $14 \%$ of comments provided feed-forward goals. \\
Informative/Specific & $\bullet$ & $35 \%$ of comments were informative or specific. \\
Metacognitive & $\bullet$ & $37 \%$ of comments were metacognitive questions. \\
\hline
\end{tabular}

Note: Percentages are based on a sampling of class segments totaling 25 minutes of dialogic whole group feedback.

It is evident that the characteristics of feedback necessary to support PBL were addressed in this course. Data from Tables 4 and 5 show that motivating feedback was given most often in written form, whereas metacognitive feedback occurred most often during verbal dialogue. Informative or specific feedback was given frequently in this course, perhaps due to the complexity of the tasks at hand and the lack of prior knowledge among students in the class. Timeliness and frequency of the feedback most often depended on the students' utilization of feedback opportunities provided in the course. The following section explores this area more closely.

How were students utilizing feedback opportunities? As feedback can vary depending on student needs and their motivation to seek out feedback opportunities, it is critical to look at how students chose to use the feedback opportunities in this course. The Blackboard learning management system was used to determine how often groups were posting drafts, activities, and comments in the group discussion and team discussion areas for instructor feedback, peer feedback, and self-assessments. Emails to the instructor were also calculated. Because all work products were done as teams in the 
course, the results show team utilization of Blackboard rather than that of individual students. Table 6 highlights the frequency with which teams utilized these feedback opportunities.

Table 6

Students Utilizing Feedback Opportunities

\begin{tabular}{lrrrrrrr}
\hline & Team A & Team B & Team C & Team D & Team E & Team F \\
\hline Team Communication & 0 & 4 & 0 & 2 & 0 & 0 \\
Reflective Posts & 1 & 1 & 1 & 3 & 2 & 2 \\
Questions Raised & 0 & 1 & 0 & 0 & 0 & 2 \\
Feedback to Peers & 2 & 0 & 0 & 1 & 1 & 1 \\
Project Drafts and Finals & 9 & 3 & 2 & 3 & 3 & 3 \\
Other Posts & 10 & 12 & 9 & 10 & 10 & 16 \\
Total Posts & 22 & 21 & 12 & 19 & 16 & 24 \\
Instructor Feedback & 6 & 4 & 2 & 4 & 2 & 11 \\
\hline
\end{tabular}

Note: The numbers note the frequency with which the team utilized each feedback opportunity.

As evident in Table 6, few teams utilized the Blackboard LMS to communicate as a team, ask questions, and provide feedback to peers. These practices only made up $10 \%$ of the total usage altogether. Some teams did use email to communicate with the instructor instead of through Blackboard, and there was no way to know how often peers communicated with each other through email or other communication tools such as Skype, Google Drive, Dropbox. The majority of posts (78.9\%) were project drafts, final drafts, and class assignments. Reflective posts made up $8.8 \%$ of the overall posts. It was noted that the more frequently a team posted in Blackboard in total, the more often they received feedback from the instructor.

What were students' perceptions about the feedback and feed-forward provided in the course? Data was collected using a survey to determine students' perception about how formative feedback was delivered, the effectiveness of each mode and method, as well as how students felt they utilized the feedback and course materials. Table 7 indicates the level of satisfaction students had with how the instructor provided formative feedback throughout the course. It was found that students agreed overall that formative 
feedback was effective in this online graduate level PBL course, with a fairly low standard deviation. Further analysis showed that the most highly rated characteristics $(\mathrm{M}=4.2500)$ were feedback that (a) clarified good performance (goals, criteria, standards); (b) provided opportunities to repeat the same task performance feedback cycle by allowing re-doing; and (c) was relevant to the task at hand and their needs. The lowest ratings $(M=3.750)$ was given to feedback that clarified task requirements and made criteria for complex tasks explicit. One student surveyed disagreed that feedback was descriptive both in writing and oral modes. However, other classmates agreed or strongly agreed with this statement. It might be concluded that students felt the performance criteria was clear and relevant (feed-up), but could have been more specific to support complex tasks.

\section{Table 7}

\section{Student Perception of Formative Feedback}

\begin{tabular}{lrr}
\hline Statement & M & SD \\
\hline $\begin{array}{l}\text { Various forms of feedback assisted me in reflecting and self- } \\
\text { assessing my learning. }\end{array}$ & 4.125 & .35 \\
$\begin{array}{l}\text { The instructor's formative feedback helped clarify good performance } \\
\text { (goals, criteria, standards). }\end{array}$ & 4.250 & .46 \\
$\begin{array}{l}\text { The formative feedback on the assignments, quizzes, and project } \\
\text { parts provided delivered high quality information about students' }\end{array}$ & 4.125 & .64 \\
$\begin{array}{l}\text { learning. } \\
\text { Feedback clarified task requirements. }\end{array}$ & 3.750 & .71 \\
$\begin{array}{l}\text { Feedback was descriptive both in writing and oral. } \\
\text { Feedback made criteria for complex tasks explicit. }\end{array}$ & 3.875 & .83 \\
$\begin{array}{l}\text { Feedback provided opportunities to repeat the same task performance } \\
\text { feedback cycle by allowing re-doing. }\end{array}$ & 4.250 & .76 \\
$\begin{array}{l}\text { Feedback was relevant to the task at hand and my needs. } \\
\text { Feedback assisted me to know what is expected and how to get there. }\end{array}$ & 3.875 & .46 \\
\hline
\end{tabular}

$\mathrm{N}=8$

5 Point Scale: 0=N/A, 1=Strongly Disagree, 2=Disagree, 3=Neutral, 4=Agree, 5=Strongly Agree

Further analysis was conducted on the students' perceptions on their use of course materials and instructor feedback (see Table 8). This data indicated slightly more variance ( $\mathrm{SD}>.53$ on all items) among 
students, and it was more difficult to draw conclusions. It may be important to note, however, that a majority of students selected were either neutral or disagreed that they "did not know what to expect, thus I sought the instructor's feedback." It is unclear whether they felt they knew what was expected, or if they felt they did not seek out the instructor's help. Perhaps this was the reasoning for so many neutral responses.

Table 8

Student use of Course Materials and Feedback

\begin{tabular}{lcc}
\hline \multicolumn{1}{c}{ Statement } & M & SD \\
\hline $\begin{array}{l}\text { I constructed a personal interpretation of the requirements and } \\
\text { properties of the tasks that I had to complete. }\end{array}$ & 3.875 & .64 \\
$\begin{array}{l}\text { I formulated my own task goals and engaged in actions to achieve } \\
\text { these goals by applying tactics and strategies of my own. }\end{array}$ & 4.125 & .64 \\
$\begin{array}{l}\text { I monitored my performance and used my own self-assessment to } \\
\text { generate feedback to improve. }\end{array}$ & 4.000 & .53 \\
I did not know what to expect, thus I sought instructor's feedback. & 3.250 & .71 \\
\hline $\begin{array}{l}\text { N=8 } \\
\text { 5 Point Scale: 0=N/A, 1=Strongly Disagree, 2=Disagree, 3=Neutral, 4=Agree, } \\
\text { 5=Strongly Agree }\end{array}$ & &
\end{tabular}

Overall, students were satisfied with the modes and methods of delivering feedback in this course (see Table 9). Students were most satisfied with written comments on assignments and other work products $(\mathrm{M}=4.375)$ as well as the effectiveness of examples and sample projects $(M=4.250)$. Least effective were the automated electronic forms of feedback. Two possible reasons for this could be that there was only one opportunity in the course for electronic automated feedback, or that students were not aware of how to properly receive this feedback after taking the test.

Of all the survey items, the most telling were the students' comments on the open-ended questions (Table 10). When asked overall, how they evaluated the quality and appropriateness of the feedback in this course, almost all the students surveyed stated that they felt it was effective, of good quality, and essential to their success on assignments. Only one student gave a suggestion pertaining 
to the organization of the learning management system. This led to the second open-ended question in this survey that asked what suggestions the students had for possible feedback strategies. Many students indicated that a reorganization of Blackboard was necessary to help find assignments, feedback, and rubrics. Comments indicated that it was difficult to search the many places where items were located, and that they were not aware of when and where to find assignments and rubrics. Additionally, students stated that clarification of expectations (feed-up) could be improved by providing more examples of quality performance or increasing the number of one-on-one instructor meetings. Based on the comments, it is possible to assume that students were satisfied with the feedback they received but wished that feed-up information was easier to find and use to improve performance before feedback was given.

Table 9

Student Perception of Feedback Modes and Methods

\begin{tabular}{lcc}
\hline \multicolumn{1}{c}{ Statement } & M & SD \\
\hline One-on-one or team meeting was effective. & 4.000 & .53 \\
Electronic automated feedback was effective. & 3.875 & .64 \\
Class discussion and instruction was effective. & 4.000 & .53 \\
General explanation and clarification of criteria was effective. & 4.000 & .53 \\
Examples and sample projects and responses were effective. & 4.250 & .71 \\
Break down of the tasks/requirements was effective. & 4.125 & .64 \\
Written comments on assignments and other work products were & 4.375 & .74 \\
effective. & & \\
\hline
\end{tabular}

$\mathrm{N}=8$

5 Point Scale: 0=N/A, 1=Strongly Disagree, 2=Disagree, 3=Neutral, 4=Agree, 5=Strongly Agree

\section{How did feedback and feed-forward strategies influence student} performance? According to the literature, feedback and feedforward strategies are necessary for students to be successful in a PBL course, especially in an online environment. It is often noted, however, that motivation and self-regulation are necessary for students to benefit from feedback and to become successful in the types of critical thinking activities needed in this course. Due to this element, data collected on the types and frequency of team feedback in relation to student performance were compared (see Tables 11 and 
12). Table 11 highlights how effectively students utilized feedback opportunities to improve performance, while Table 12 focuses on the instructor's implementation of feedback to help teams improve. Based on the data, it is difficult to claim that the frequency or type of feedback helped students who received high grades on projects. It is however evident that high-achieving teams did receive more motivating feedback. This is likely due to the fact that the comments about good performance were in direct relation to high scores on the rubric, which meant that the instructor let teams know what they were doing well, while also scoring them high on the rubric.

Table 10

Student Comments about Feedback in the Course

\begin{tabular}{|c|c|}
\hline Assigned Codes & Student Comments \\
\hline $\begin{array}{l}\text { Effectiveness of } \\
\text { Feedback }\end{array}$ & $\begin{array}{l}\text { - Overall, the quality and appropriateness of the feedback } \\
\text { was effective. } \\
\text { - Feedback on projects was usually useful information } \\
\text { that helped me make changes and understand what I } \\
\text { could have done a little better. It was appropriate to the } \\
\text { task at hand. } \\
\text { - The feedback has been crucial to my success in this } \\
\text { course. Every bit of feedback both noticed and unnoticed } \\
\text { has helped me to gain a better understanding of the } \\
\text { course materials and processes. All feedback was given } \\
\text { in appropriate forms, quality, and timeliness. } \\
\text { - Very effective to get feedback throughout the course. } \\
\text { The quality was good and challenged to be better. }\end{array}$ \\
\hline
\end{tabular}

Design of Course LMS
- The only challenge I found was sometimes it was difficult to navigate the Blackboard and find where tasks/ assignments were posted. There would be assignments posted that I didn't know about.

- It was a little difficult finding some of the rubrics. I spend a lot of time just sifting through the website. If you could organize the blackboard page a little better and check links before that week, it would help students that need to work ahead some weeks rather than falling behind on busier weeks.

- There are several varieties of feedback and places to find information throughout the course, but sometimes it can be overwhelming to have so many different places to look or check. 


\begin{tabular}{ll}
\hline \multicolumn{1}{c}{ Assigned Codes } & \multicolumn{1}{c}{ Student Comments } \\
\hline Clarification of & - $\begin{array}{l}\text { Sometimes I would like more concrete examples of what } \\
\text { would constitute an above average answer in the written } \\
\text { feedback. }\end{array}$ \\
- & More examples presented. \\
- & More clarification on expectations. \\
- & More instructor meetings for each step. \\
- Also, having the rubrics at the beginning of a project & is more helpful than in the middle or towards the end, \\
& because I ended up going back and adding things after \\
& finding the rubric. \\
- & A potential for this class and many others in the MIT \\
program would be team skill feedback from the \\
for Feessor (as applicable and possible) and from team \\
partners. This feedback would definitely best to happen \\
at the end of the course but perhaps also midway through \\
to encourage positive changes that can be observed at the \\
end of the course. \\
Less discussion and more in class activities.
\end{tabular}

What is most evident when comparing the data in Tables 11 and 12 is the effect that posting in Blackboard had on overall performance. The two teams that posted the fewest amount of times in Blackboard (only 12 and 16 times) also showed the lowest performance on one or both of the projects $(70,88,89)$. Students who were not seeking out as much instructor support struggled more in the beginning. These two teams, however, did receive the most informative/ specific feedback $(53.1 \%$ and $48.2 \%)$ and relatively high rates of metacognitive feedback (15.6\% and 17.2\%). Team E was able to use this highly effective feedback provided to improve critical thinking about the task and to improve both the scores from Projects I and II. Team C's score did not improve, but this could have been because this team consisted of only one person. As PBL is highly collaborative in nature, Team $\mathrm{C}$ may have had difficulty thinking through the complex problem solving tasks alone.

It is also important to note that in the end, all teams scored relatively well on both projects (85-99\%). This finding suggests that the levels of motivating-feedback, feed-up and feed forward goals, informative/specific feedback, and metacognitive feedback were adequate to support student achievement. Team B did not seek as much help from the instructor via posting drafts and assignments, 
but was still successful. This might have been due to the team's overall understanding of the material and their confidence that they were moving in the right direction.

\section{Table 11}

Team Feedback and Student Performance

\begin{tabular}{lrrrrrrr}
\hline & Team & Team & Team & Team & \multicolumn{2}{c}{ Team } & \multicolumn{2}{c}{ Team } \\
& \multicolumn{1}{c}{ A } & \multicolumn{1}{c}{ B } & \multicolumn{1}{c}{ C } & \multicolumn{1}{c}{ D } & \multicolumn{1}{c}{ E } & \multicolumn{1}{c}{ F } \\
\hline $\begin{array}{l}\text { Projects/Drafts Submitted } \\
\text { (Frequency) }\end{array}$ & 3 & 2 & 2 & 4 & 3 & 5 \\
Motivating Feedback (\%) & 14.8 & 58.3 & 21.9 & 22.9 & 31 & 29.2 \\
Feed-forward Goals (\%) & 18.5 & 12.4 & 9.4 & 20.8 & 3.4 & 15.4 \\
Informative/Specific Feedback & 42.6 & 16.7 & 53.1 & 47.9 & 48.2 & 36.9 \\
(\%) & & & & & & \\
Metacognitive Feedback (\%) & 24 & 12.5 & 15.6 & 8.3 & 17.2 & 23.1 \\
Project I Grade (\%) & 90 & 93 & 89 & 93 & $70 / 93$ & 93 \\
Project II Grade (\%) & 85 & 99 & 88 & 98 & 99 & 98 \\
\hline
\end{tabular}

Note: The numbers in row 1 indicate the frequency of students' submission of projects or drafts to be reviewed. The numbers in rows 2-5 indicate the percentage of each type of feedback received by the team. The last 2 rows are the grades teams received on final projects. Team E was afforded two attempts at Project I but both scores are indicated to show team improvement.

\section{Table 12}

\section{Team Feedback and Student Performance}

\begin{tabular}{lcccccc}
\hline & Team & Team & Team & Team & Team & Team \\
& A & B & C & D & E & F \\
\hline Projects/Drafts Submitted & 3 & 2 & 2 & 4 & 3 & 5 \\
Motivating Feedback (\%) & 14.8 & 58.3 & 21.9 & 22.9 & 31 & 29.2 \\
Feed-forward Goals (\%) & 18.5 & 12.4 & 9.4 & 20.8 & 3.4 & 15.4 \\
Informative/Specific Feedback (\%) & 42.6 & 16.7 & 53.1 & 47.9 & 48.2 & 36.9 \\
Metacognitive Feedback (\%) & 24 & 12.5 & 15.6 & 8.3 & 17.2 & 23.1 \\
Project I Grade (\%) & 90 & 93 & 89 & 93 & $70 / 93$ & 93 \\
Project II Grade (\%) & 85 & 99 & 88 & 98 & 99 & 98 \\
Note: The numbers in row 1 indicate the frequency of students' submission of \\
projects or drafts to be reviewed. The numbers in rows 2-5 indicate the percentage \\
of each type of feedback received by the team. The last 2 rows are the grades teams \\
received on final projects. Team E was afforded two attempts at Project I but both \\
scores are indicated to show team improvement.
\end{tabular}




\section{DISCUSSION AND CONCLUSIONS}

A literature review on feedback and PBL aided in designing and developing two design models that were then implemented in an online graduate course. The characteristics and strategies suggested in the models shown in Figure 1 and 2 have proven to support student achievement on course projects and activities. All students in the course were able to complete Projects I and II with an average or above average performance score. The timely and frequent feedback allowed students to make necessary changes to project parts and assignments to improve performance, and students commented that this helped them achieve success in this course. As the frequency of feedback was dependent upon student request, those that needed more frequent feedback during the acquisition of learning (Salmoni, Schmidt, \& Walter, 1984) could benefit from it, but those did not need frequent feedback, such as Team B, could receive the moderate amount necessary to be successful (Lam et al., 2011).

The motivating, informative/specific feed-up, feedback and feedforward goals provided a reference for areas of student improvement. Comments in class indicated that students were "using the feed-up and feedback to make changes" and thankful "for such specific feedback." A balance of these three types of feedback along with metacognitive questioning supported student improvement. Specific and informative feedback provided direct information that students could use to shape a foundation for understanding of the content (Goodman, Wood, \& Hendrickx, 2004). The feed-forward goals helped students see the next steps needed for learning, and how their previous efforts could be changed to make improvements (Hattie \& Timperely, 2007; Nicol \& Macfarlane-Dick, 2006). Metacognitive questioning allowed learning to shift from the teacher to the learner (Salder, 1989) and forced students to think of ways to answer those questions to improve their work (Barrows, 1988).

Although small group and peer feedback were delivered in this course mainly through whole group class discussions, often students learned from other's processes during this dialogue. Hearing the mistakes, successes, and suggestions of other groups allowed teams to take in this information and then apply it to areas of their own work. Self-assessment opportunities, although not a direct 
requirement for this course, were afforded to students. Some teams utilized this opportunity through Blackboard more often than others. However, there was no clear way to assess whether or not teams utilized this strategy other than through the survey responses. It is recommended that in future, students could be required to do a team self-assessment on each project draft submitted to allow them to think through their performance and find their own strengths and weaknesses first.

Blackboard played a critical part in the success of students in this course, but also posed some concerns. PBL in an online environment requires careful attention to the learning and teaching tools in this virtual learning space (Savin-Baden, \& Wilkie, 2006). The instructor provided various forms of feed up, feedback, and feedforward strategies within this course management system. Students, however, commented that these learning tools were difficult to locate, or did not seem to work when needed. Findings suggest that it may be necessary for students to be offered instructions at the beginning of the course on exactly where all information would be located, where they are to post, and how they can communicate with each other and the instructor. This information should be clear and straightforward, perhaps with only one route to finding it. Keeping this step simple will allow students to focus on the difficult tasks and critical thinking necessary for PBL. Instructors may also consider ensuring that all materials are prepared at the start of the course for students to prepare themselves and move at the pace that they find necessary to self-regulate throughout the course.

Although there was little direct correlation between student feedback and high performance on the project parts, findings did show that students who did not seek a lot of feedback from the instructor early on had a difficult time grasping the concepts necessary to perform well on projects. This suggests that student self-regulation is an essential component to success in PBL (Torp \& Sage, 2002; Barrows, 1996). Students need to actively seek out the instructor's feedback and support when they perceive they are having difficulties. They can do so by asking questions, submitting project parts for instructor review, and asking for clarification of concepts or criteria. In this study, Blackboard personal or team areas, Blackboard discussion forums, email, whole class discussions, and team meetings (either virtual or face to face) were all utilized to communicate with the instructor for 
these purposes. Some teams, as indicated in the previous section, accessed these options more often than others. Some teams received a higher frequency of feedback and performed well on tasks, while some sought out very little feedback and also performed well. The latter teams perhaps did not need as much support and were able to self-regulate through in-class discussions, the feed-up strategies given, and prior knowledge brought to the course.

The social aspects of learning provided interactions among peers and the instructor that were critical to the development and the understanding of course content (Richardson \& Swan, 2003). The social setting of this course varied from student to student. Some students were working from home and attending class virtually through the WebEx teleconferencing system while others were attending class face to face. Some teams were a mixture of both environments with one team member on campus and the other attending virtually. During class discussions, students from both learning environments contributed to the conversations and shared about their projects and learning. It was clear that students felt comfortable sharing ideas and providing input. These authentic evaluative experiences in which the instructor and peers can provide feedback and input made the social interaction meaningful (Ertmer et al., 2007) and improved overall satisfaction (Richardson \& Swain, 2003). One student at a distance pointed out that being in class could have been beneficial to the overall course experience, suggesting that a face-to-face environment is preferred by some students. This did not, however, interfere with the student's overall performance on the course projects. Students also agreed that team meetings and class discussions, both social forms of instruction, contributed effectively towards overall success in this course.

\section{Future Research in Problem-based Learning and Formative Feedback}

This study brings to light the importance of formative feedback in problem or project-based learning. It is necessary that all forms including feed-up, feedback, and feed-forward be present and continue to support student success throughout the entire course. Characteristics of feedback should include frequency and timeliness which support individual or team needs, motivating feedback, 
informative or specific feedback, and metacognitive questioning. These characteristics should also be delivered in various modes such as written, verbal, and dialogic; and through various methods such as one-on-one, peer or small-group, and self-assessment.

Further research is necessary to address the areas of students' individual differences, specifically in how they react to and utilize the feedback model. Future research should also explore how to prepare students for the disposition necessary to receive feedback. Another area for future research is the importance of determining student interests and abilities through pre-assessment to adjust feedback strategies such as frequency, timeliness, and specificity based on individual differences. Other areas of research that can help develop the idea of feedback in PBL include the student selfregulation necessary in this approach. This study concluded that a fair amount of self-regulation is necessary in order to be successful in PBL, especially knowing how to use and when to ask for feedback. Further studies could also focus on why some students choose to seek more feedback, how to support students who seek more feedback, and how to teach students to understand when they should request for help or clarification. Another important factor to consider is the length of time required by instructors to deliver this multifaceted feedback. Dialogic feedback, informative and specific written feedback, and one-on-one team meetings appear to be the some of the most desirable characteristics implemented.

\section{REFERENCES}

Anderson, R. C., Kulhavy, R. W., \& Andre, T. (1972). Feedback procedures in programmed instruction. Journal of Educational Psychology, 62(2), 148-156.

Ashford, S. J. (1986). Feedback-seeking in individual adaptation: A resource perspective. Academy of Management Journal, 29 (3), 465-487.

Ashford, S. J., Blatt, R., \& VandeWalle, D. (2003). Reflections on the looking glass: A review of research on feedback-seeking behavior in organizations. Journal of Management, 29 (6), 773- 799 .

Bandura, A. (1977). Social learning theory. New York: General Learning Press. 
Barrows, H. S. (1988). The tutorial process. Springfield, Ill: Southern Illinois University School of Medicine.

Barrows, H. S. (1996). Problem-based learning in medicine and beyond: A brief overview. New Directions for Teaching and Learning, Winter 1996 (68), 3-12.

Black, P. \& William, D. (1998), Inside the Black Box: Raising Standards through Classroom Assessment, Phi Delta Kappan International, 80(2), pp. 139-148.

Boud, D., Lawson, R. \& Thompson, D. G. (2013). Does student engagement in self-assessment calibrate their judgement over time? Assessment and Evaluation in Higher Education, 38(8), 941-956.

Brookhart, S. M. (2008). How to give effective feedback to your students. Alexandria, VA: Association for Supervision and Curriculum Development.

Brophy, J. E. (1981). Teacher praise: A functional analysis. Review of Educational Research, 51(1), 5-32.

Carless, D., Salter, D., Yang, M., \& Lam, J. (2011). Developing sustainable feedback practices. Studies in Higher Education, 36(4), 395-407.

Chhokar, J. S., \& Wallin, J. A. (1984). A field study of the effect of feedback frequency on performance. Journal of Applied Psychology, 69(3), 524-530.

Clariana, R. B. (1999). Differential memory effects for immediate and delayed feedback: A delta rule explanation of feedback timing effects. A Presentation at the Annual Convention of the Association for Educational Communications and Technology, February, 1999 in Houston, TX. (ERIC Document Reproduction Center ED 430 550).

Clark, R. E., Kirschner, P. A., \& Sweller, J. (2012,June 06). Putting Students on the Path to Learning: The Case for Fully Guided Instruction. American Educator, 36(1), 6-11.

Cohen, V. B. (1985). A reexamination of feedback in computerbased instruction: Implications for instructional design. Educational Technology, 25(1), 33-37.

Corbett, A. T., \& Anderson, J. R. (2001, March). Locus of feedback control in computer-based tutoring: Impact on learning rate, achievement and attitudes. In Proceedings of the SIGCHI conference on Human factors in computing systems (pp. 245252). ACM. 
Cramp, A. (2011). Developing first-year engagement with written feedback. Active Learning in Higher Education, 12(2), 113-124.

Epstein, R. M., Siegel, D. J., \& Silberman, J. (2008). Selfmonitoring in clinical practice: a challenge for medical educators. Journal of Continuing Education in the Health Professions, 28(1), 5-13.

Ertmer, P. A., \& Simons, K. D. (2006). Jumping the PBL Implementation Hurdle: Supporting the Efforts of K-12 Teachers. Interdisciplinary Journal of Problem-Based Learning, 1(1), 40-54.

Ertmer, P. A., Richardson, J. C., Belland, B., Camin, D., Connolly, P., Coulthard, G., ... \& Mong, C. (2007). Using peer feedback to enhance the quality of student online postings: An exploratory study. Journal of Computer Mediated Communication, 12(2), 412-433.

Goodman, J. S., Wood, R. E., \& Hendrickx, M. (2004). Feedback specificity, exploration, and learning. Journal of Applied Psychology, 89(2), 248.

Hattie, J., \& Timperley, H. (2007). The power of feedback. Review of Educational Research, 77(1), 81-112.

Hendry, G., White, P., Herbert, C. (2016). Providing exemplar based 'feedforward' before an assessment: The role of teacher explanation. Active Learning in Higher Education, 17(2), 99-109.

Hmelo-Silver, C. E. (2004). Problem-based learning: What and how do students learn? Educational Psychology Review, 16 (3), 235-266.

Hundal, P. S. (1969). Knowledge of performance as an incentive in repetitive industrial work. Journal of Applied Psychology, 53(3), 224-226.

Johnson, D., \& Johnson, R. (1993). Cooperative learning and feedback in technology-based instruction. In J. Dempsey \& G. Sales (Eds.), Interactive instruction and feedback (pp. 133-157). Englewood Cliffs, NJ: Educational Technology Publications.

Kulhavy, R. W., and Anderson, R. C. (1972). Delay-retention effect with multiple-choice tests. Journal of Educational. Psychology, 63 (5), 505-512.

Lam, C. F., DeRue, D. S., Karam, E. P., \& Hollenbeck, J. R. (2011). The impact of feedback frequency on learning and task performance: Challenging the "more is better" assumption. Organizational Behavior and Human Decision Processes, 116(2), 217-228. 
Lam, R. (2010). A peer review training workshop: Coaching students to give and evaluate peer feedback. TESL Canada Journal, 27(2), 114.

Larmer, J. (2014). Project-based learning vs. problem-based learning vs. XBL. Edutopia. Retrieved from www.edutopia.org.

Markham, T., Larmer, J., Ravitz, J. L., \& Buck Institute for Education. (2003). Project based learning handbook: A guide to standards-focused project based learning for middle and high school teachers. Novato, CA: Buck Institute for Education.

Marx, R. W., Blumenfeld, P. C., Krajcik, J.S., \& Soloway, E. (1997). Enacting project- based science: Challenges for practice and policy. Elementary School Journal, 97, 341-358.

Mathan, S., \& Koedinger, K. R. (2003). Recasting the feedback debate: Benefits of tutoring error detection and corrections kills. In H. U. Hoppe, M. F. Verdejo, and J. Kay (Eds.), Artificial intelligence in education: Shaping the future of learning through intelligent technologies. Proceedings of AIED 2003 (pp. 39-46). Amsterdam, The Netherlands: IOS.

Nicol, D. J., \& MacfarlaneDDick, D. (2006). Formative assessment and selflregulated learning: A model and seven principles of good feedback practice. Studies in Higher Education, 31(2), 199-218.

Nitko, A. J. (2004). Educational assessment of students. Upper Saddle River, N.J: Merrill.

Perrenet, J., Bouhuijs, P., \& Smits, J. (2000). The suitability of problem-based learning for engineering education. Theory and Practice Teaching in Higher Education, 5(3), 45-348.

Phye, G. D., \& Andre, T. (1989). Delayed retention effect: Attention, perseveration, or both? Contemporary Educational Psychology, 14 (2), 173-185.

Price, B. (1997). Defining quality student feedback in distance learning. Journal of Advanced Nursing, 26(1), 154-160.

Relan, A., \& Gillani, B. B. (1997). Web-based instruction and the traditional classroom: Similarities and differences. In Badrul, H. Khan (Ed.), Web based instruction (pp. 41-46). New Jersey: Educational Technological Publication.

Richardson, J. C., \& Swan, K. (2003). An examination social presence in online courses in relation to students' perceived learning and satisfaction. Journal of Asynchronous Learning, $7(1), 68-88$. 
Sadler, D. R. (1989). Formative assessment and the design of instructional systems. Instructional Science, 18(2), 119-144.

Sadler, D. R. (2010). Beyond feedback: Developing student capability in complex appraisal. Assessment \& Evaluation in Higher Education, 35(5), 535-550.

Sadler, D. R. (2013). Opening up feedback: Teaching learners to see. In Merry, S., Price, M., Carless, D., \& Taras, M. (Eds.) Reconceptualising feedback in higher education: developing dialogue with students (Chapter 5, pp. 54-63). London: Routledge.

Salmon, G. (2002). E-tivities: The key to active online learning. London: Kogan Page.

Salmoni, A. W., Schmidt, R. A., \& Walter, C. B. (1984). Knowledge of results and motor learning: a review and critical reappraisal. Psychological Bulletin,95(3), 355.

Sargeant, J., Armson, H., Chesluk, B., Dornan, T. Eva, K., Holmboe, E., ... Van der Vieuten, C. (2010). The process and dimensions of informal self-assessment: A conceptual model. Academic Medicine, 85, 1212-1220.

Savery, J. R. (2009). Problem-based approach to instruction. In C. M. Reigeluth \& A. A. Carr-Chellman (Eds.), Instructionaldesign theories and models: Building a common knowledge base (Vol. III, pp. 143-165). New York: Routledge.

Savery, J. R., \& Duffy, T. M. (1995). Problem based learning: An instructional model and its constructivist framework. Educational Technology, 35(5), 31-38.

Savin-Baden, M., \& Wilkie, K. (2006). Problem-based learning online. Maidenhead: Open University Press.

Schmidt, R. A., Young, D. E., Swinnen, S., \& Shapiro, D. C. (1989). Summary knowledge of results for skill acquisition: support for the guidance hypothesis. Journal of Experimental Psychology: Learning, Memory, and Cognition, 15(2), 352.

Schwartz, F., \& White, K. (2000). Making sense of it all: Giving and getting online course feedback. In K. W. White \& B. H. Weight (Eds.), The online teaching guide: A handbook of attitudes, strategies, and techniques for the virtual classroom (pp. 57-72). Boston: Allyn and Bacon.

Simonson, M., Smaldino, S. E., Albright, M., \& Zvacek, S. (2015). Teaching and learning at a distance: Foundations of distance education. (6th ed.). New York: Information Age Publishers. (eText) 
Song, S. H., \& Keller, J. M. (2001). Effectiveness of motivationally adaptive computer assisted instruction on the dynamic aspects of motivation. Educational Technology, Research \& Development, 49 (2) 5-22.

Sweller, J., Kirschner, P. A., \& Clark, R. E. (June 06, 2007). Why minimally guided teaching techniques do not work: A Reply to Commentaries. Educational Psychologist, 42 (2), 115-121.

Torp, L., \& Sage, S. (2002). Problems as possibilities: Problembased learning for K-16 education. Alexandria, VA: Association for Supervision \& Curriculum Development.

Van, M. J. J. G., Clark, R. E., \& de, C. M. B. M. (June 01, 2002). Blueprints for complex learning: The 4C/ID-model. Educational Technology Research and Development, 50(2), 39-61.

Vancouver, J. B., \& Morrison, E. W. (1995). Feedback inquiry: The effect of source attributes and individual differences. Organizational Behavior and Human Decision Processes, 62 (4), 276-285.

Wijnia, L. (2014, November 14). Motivation and achievement in problem-based learning: The role of interest, tutors, and selfdirected study. Erasmus University Rotterdam. Retrieved from http://hdl.handle.net/1765/77158. 


\section{Appendix A}

\section{Synthesis of the literature on forms, functions and features of feedback}

\begin{tabular}{|c|c|c|}
\hline Feedback & Description & Definition \\
\hline $\begin{array}{l}\text { Forms of } \\
\text { Feedback }\end{array}$ & Written & $\begin{array}{l}\text { Written feedback is a genre in which the desire } \\
\text { is to give clearly communicated messages to the } \\
\text { learner in a written form. When using this mode of } \\
\text { feedback, it is necessary to consider the tone and } \\
\text { word choice as other social cues are not present } \\
\text { to convey meaning. It is suggested that this type } \\
\text { of feedback tends to work better in summative or } \\
\text { graded assignments as students often look straight } \\
\text { to the grade and may not pay close attention to the } \\
\text { specific feedback (Brookhart, 2008). }\end{array}$ \\
\hline
\end{tabular}

Oral Oral feedback is perhaps one of the most important forms of feedback when considering the relationship between the instructor and the student. It often occurs informally during realtime observation of a student's work or formally during one-on-one conferencing (Brookhart, 2008). Oral feedback can be given during class discussions to correct whole group misconceptions or can be used to immediately praise or correct an individual student's performance. This real-time feedback allows for a quick and timely response that is often necessary during the acquisition of difficult learning tasks (Corbett \& Anderson, 2001).

Dialogic The limitations of simply providing one way written or oral feedback leave the learner with room for incorrect interpretation, ignored suggestions, and no way to ask questions or respond. Distance and mass education settings also pose a problem for the relationship between student, instructor, and peers. Dialogic feedback provides a format for interactive exchange between the learner and the instructor/tutor, or the learner and peers. This approach involves a two-way conversation which can include how well a student is meeting quality standards specific to assignment criteria, what good performance will look like, and how the learner can proceed from this point forward (Careless, Salter, Yang, \& Lam, 2011). 


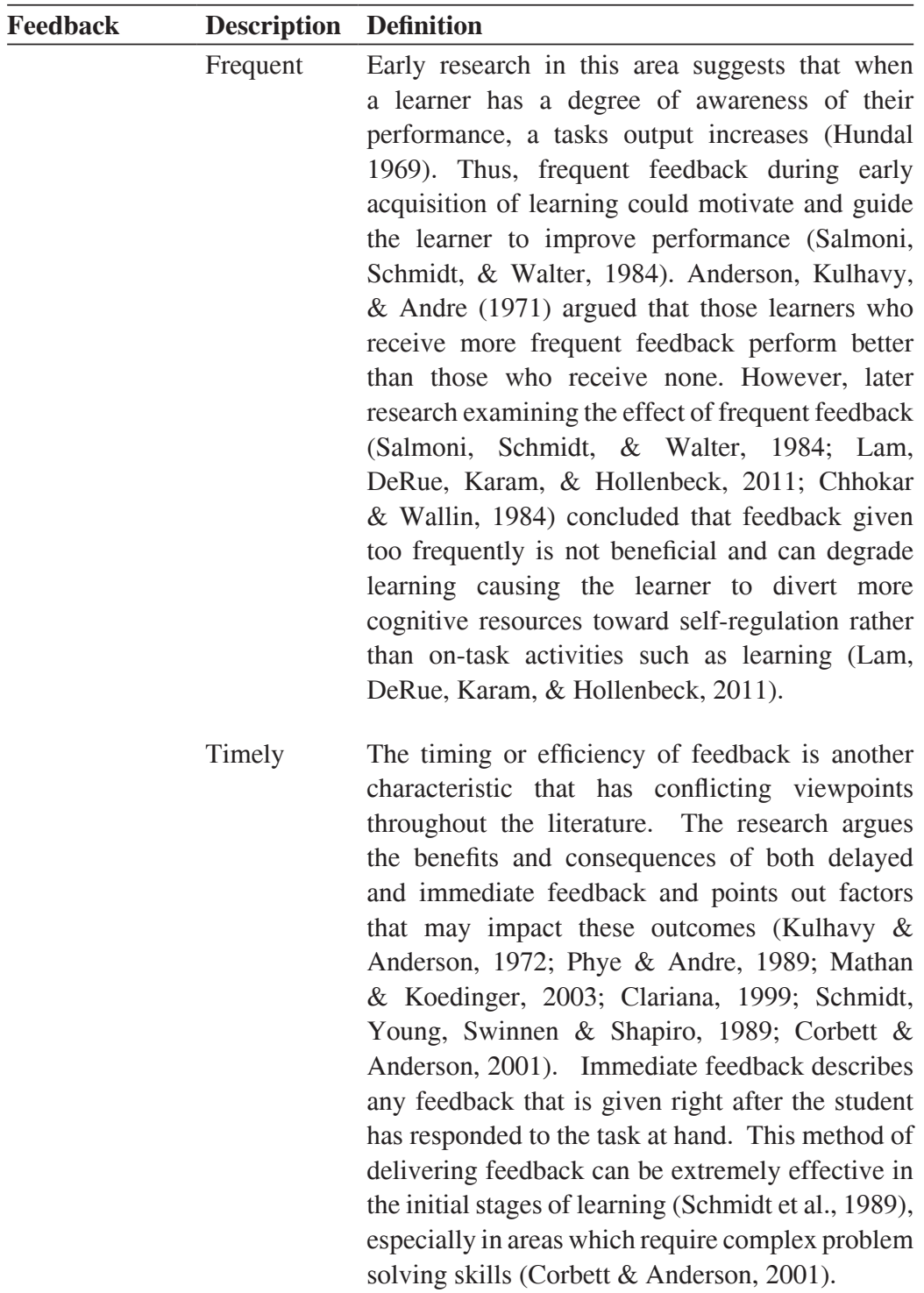

Functions of Directive

Directive feedback tells the student what needs Feedback to be fixed or revised. Such feedback tends to be more specific (Black \& William, 1998).

Facilitative Facilitative feedback provides comments and suggestions to help guide students in their own revision and conceptualization (Black \& William, 1998). 


\begin{tabular}{lll}
\hline Feedback & Description & Definition \\
\hline Specific & Feedback specificity is referred to as, "the level \\
& of information presented in feedback messages" \\
& (Goodman, Wood, \& Hendrickx, 2004, p. \\
& 248). Feedback can be considered general and \\
& facilitative in nature, or specific and have more \\
& elaborative and direct qualities. Much like \\
& frequency, the specificity with which feedback \\
& is given has many variables which can influence \\
& its effects. For example, a high level of specific \\
& feedback in initial learning is beneficial for \\
& improved performance because students are given \\
& direct information with which they can use to \\
shape a foundation of understanding (Goodman, & Wood, \& Hendrickx, 2004).
\end{tabular}

Sources of Feedback
Instructor's one-on-one feedback

Selfassessment
Feedback from the instructor and expert of course content is often preferred by learners, especially those that view high achievement as valuable (Vancouver \& Morrison, 1995). When seeking feedback, those that are motivated to learn want to be sure they are obtaining reliable and accurate information and feel this best comes from source experts (Vancouver \& Morrison, 1995). For this feedback to support the learner it must be clearly related to the goals or criteria, help the student take action to reach those goals, and must use an instrument that delivers the feedback in a way which positively supports the learner (Nicol \& Macfarlane-Dick, 2006). Furthermore, building a positive and supportive relationship between the instructor and student is essential to the one-onone learning process (Cramp, 2011).

Self-assessment can be defined as an application of many distinct processes including the selection of appropriate external data and standards, an awareness of one's own current state, and the critical reflection of one's own performance (Sargeant et al., 2010). Epstein, Siegel, and Silberman (2008) suggest that self-assessment lies in two major domains which include 1) "the integration of high quality external and internal data to assess current performance" and 2) "the capacity for ongoing self-monitoring during everyday practice" (p. 11). When students are provided with an authentic evaluative experience in learning, the evaluative decisions begin to shift in responsibility from teacher to learner (Sadler, 1989). 
Feedback Description Definition

Students begin to learn and/or apply a variety of metacognitive and self-evaluative skills which will be critical in future professional and nonprofessional roles (Boud, Lawson, Thompson, 2013). Essential are self-monitoring skills such as noticing, self-questioning, and suspending personal judgments while assessing one's own work (Epstein, Siegel, \& Silberman, 2008).

Peer and "In the social learning system, new patterns Instructor's of behavior can be acquired through direct Small Group experience or by observing the behavior of others" Feedback (Bandura, 1977, p. 3).

Peer and small group feedback are derived from this social learning theory developed by Albert Bandura (1977). Instructional design, especially that of online environments, should incorporate social aspects of learning (Richardson \& Swan, 2003). Social learning strategies allow the instructor to share some of the responsibility of the learning with the learners (Ertmer, Richardson, Belland, \& Camin, 2007) and provide an opportunity for learners to construct knowledge in collaboration with peers. 


\title{
Appendix B
}

\section{Examples of the instructor's verbal/dialogic feedback}

\author{
Characteristics of Verbal/Dialogic Feedback \\ Feedback
}

Motivating

- "You brought up a very good point."

- "Right, so you want your learner to demonstrate ..."

- "Excellent, so what you described is ... and that is how you created your goal."

- "I think your model is very appropriate because ..."

- "At this point you may be struggling but that is ok."

Feed-Forward Goals

- "Your next step would be to start calculating how much it is going to cost you."

- "You need to now do the plan based on what you established your goals were."

- "Keep thinking about your goal, and make sure you are assessing it properly."

- "You have done the needs analysis, now start expanding on that plan for the needs and goals you identified."

- "In addition to human performance, you may want to look at the procedure."

Informative/Specific

- "Wait on creating phases until your goals are formulated."

- "Be careful not to exclude parts that do not apply to you when learning."

- "You need to make sure you are putting emphasis on the outcome."

- "Use terminology that is a bit more appealing or attractive to the reader."

- "If you take a look at my feedback, you can see how to differentiate between benchmarks and instruments."

Metacognitive

- "Is there a process that should take place?"

- "[Y]ou basically have two target groups of people that would have to master skills and knowledge, so what are your 2 goals?"

- "What should you expect after one year?"

- "Do you train the trainer at the beginning or do you follow up?"

- "Did anything puzzle you during the process?" 


\title{
Examples of the instructor's written feedback
}

\author{
Characteristics of Written Feedback \\ Feedback
Motivating - "Good, so the change is for the whole school?"
- "Good job of explaining the forces for the change."
- "Very good! The purpose of the proposed change is very clear."
- "Good, you have some estimation of the resources you need and where the funding is coming from."
- "Very good!! Excellent decision!"

Feed-Forward Goals - "The means of implementing the change will have to be defined later, and you have to explain what the stages of the whole school adoption are."

- "Do you want to include an evaluator who could track the progress you are making?"

- Make the scope of the change clear. How this phased approach expands over time and what is the final scope?"

- "... indicate if are enough resources internally to provide needed training for staff. What will be developed and how will be an implementation/ planning issue that will be decided on later."

- "You may want to include the purposes or goals targeted for this phase."

- "Consider using the model to explain how it will inform your planning and implementation of the change."

Informative/Specific - "Problem-based is not the same as project-based learning. If project-based learning is your focus use project-based, not problem-based."

- "Always start with specific goal and objectives."

- "I would have liked to see a project summary page that highlighted the project core ideas and plans...."

- "You need to make the impact of this change on the organization outcome (goals) clearer so that the value and impact of the change are measurable."

- "While your argument for a good match between the organization conditions and the model is established, it is hard to know how you would apply the change model to plan the change."

Metacognitive

- "How about curriculum and instructional materials? Do they have to change? How about scheduling and time for classes?"

- "Ok, then how will it expand?"

- "Should this be changed to benchmark?"

- "How would you use the model to plan and implement the change?"

- "How many new positions and experienced individuals?" 